\title{
EFEITOS DA INCLUSÃO DE FORRAGEM DE LEUCENA (Leucaena leucocephala (Lam.) DeWit) NA QUALIDADE DA SILAGEM DE MILHO (Zea mays L.)
}

\author{
Effects of the inclusion of leucaena (Leucaena leucocephala (Lam.) \\ DeWit) forage on corn silage quality
}

\author{
Rosana Cristina Pereira ${ }^{1}$, Antônio Ricardo Evangelista ${ }^{2}$, Joadil Gonçalves de Abreu ${ }^{3}$, \\ Pedro Nelson Cesar do Amaral ${ }^{1}$, Flávio Moreno Salvador ${ }^{1}$, Giovana Alcântara Maciel ${ }^{4}$
}

\begin{abstract}
RESUMO
Este ensaio foi realizado no Departamento de Zootecnia da Universidade Federal de Lavras-MG, com o objetivo de avaliar os efeitos da adição de níveis crescentes de forragem de leucena (Leucaena leucocephala (Lam.) DeWit) no valor nutritivo da silagem de milho (Zea mays L.). O delineamento experimental usado foi o inteiramente casualizado com cinco tratamentos e três repetições. Os tratamentos consistiram de silagens de milho contendo 0,10, 20, 30 e $40 \%$ de forragem de leucena com base na matéria verde. O material permaneceu ensilado por 30 dias em silos experimentais de canos de PVC. Determinaram-se os valores de pH e poder-tampão (PT) e os teores de MS, PB, FDN, FDA e nitrogênio amoniacal $\left(\mathrm{N}_{-} \mathrm{NH}_{3}\right)$. O aumento na proporção de leucena não alterou o teor de matéria seca das silagens e resultou em efeito linear positivo sobre os valores de $\mathrm{pH}, \mathrm{PT}, \mathrm{PB}$ e $\mathrm{N}-\mathrm{NH}_{3}$ e efeito linear negativo sobre os teores de FDN e FDA. A inclusão de forragem de leucena até o nível de $40 \%$ é uma alternativa viável para a melhoria do valor nutritivo da silagem de milho.
\end{abstract}

Termos para indexação: FDA, FDN, PB, valor nutritivo, Zea mays.

\section{ABSTRACT}

This assay was conducted at the Department of Animal Science of the University Federal of Lavras with the objective to evaluate the effects of the addition of growing levels of leucaena forage (Leucaena leucocephala (Lam.) DeWit) in the nutritive value of the corn silage (Zea mays L.). The experimental design used was the completely randomized with five treatments and three replicates. The treatments consisted of corn silage with $0,10,20,30$ and $40 \%$ of leucaena forage. The material remained ensiled for 30 days in experimental silos of PVC tubes. The values of $\mathrm{pH}$ and buffering power (BP) and the contents of DM, CP, NDF, ADF and ammonium nitrogen $\left(\mathrm{N}_{-} \mathrm{NH}_{3}\right)$ were determined. The dry matter contend of the silages was not affected by addition of leucaena. The increase in the ratio of leucaena resulted into a positive linear effect on the values of $\mathrm{pH}, \mathrm{BP}, \mathrm{PB}$ and $\mathrm{N}-\mathrm{NH}_{3}$, and a negative effect on the contents of NDF and ADF. The addition of up to $40 \%$ of leucaena forage in the mixture of the silage is a viable alternative to the improvement of the nutritive value of corn silage.

Index terms: CP, NDA, NDF, nutritive value, Zea mays.

(Recebido para publicação em 17 de dezembro de 2003 e aprovado em 24 de março de 2004)

\section{INTRODUÇÃO}

A baixa disponibilidade e valor nutritivo das pastagens, notadamente no período da seca, são os fatores que mais contribuem para a perda de peso e diminuição de produção de leite e carne dos animais. Em todo o mundo, a conservação de alimentos, principalmente de volumosos, tem sido utilizada como uma técnica que permite a utilização desses alimentos em qualquer época do ano. A ensilagem é uma boa opção para o aproveitamento do excesso de forragem produzida durante a estação de maior crescimento das plantas forrageiras, garantindo a alimentação adequada na época das secas.

O milho, devido à facilidade de cultivo, adaptabilidade, alta produção de massa, facilidade de fermentação no silo, bom valor energético e alto consumo pelos animais, é uma das gramíneas mais utilizadas para a confecção de silagem (EVANGELISTA e LIMA, 2000; OLIVEIRA, 2001). Para a ensilagem do milho, não há a necessidade de aditivos para estimular a fermentação, desde que colhido com teores de matéria seca adequados. Porém,

\footnotetext{
1. Zootecnistas, M.Sc., Doutorandos(as) do Departamento de Zootecnia da Universidade Federal de Lavras/UFLA - Caixa Postal 37 - 37200 000 - Lavras, MG.

2. Engenheiro Agrônomo, D.Sc., Professor do Departamento de Zootecnia/UFLA, bolsista CNPq

3. Engenheiro Agrônomo, M.Sc., Doutorando do Departamento de Zootecnia/UFLA, bolsista CAPES.

4. Estudante de Graduação em Zootecnia, Departamento de Zootecnia/UFLA, bolsista PIBIC-CNPq.
} 
segundo Evangelista et al. (1984) e Vilela (1998), a silagem de milho apresenta um baixo teor de proteína, o que constitui uma limitação ao seu uso, principalmente para animais de altas exigências nutricionais. Uma alternativa para melhorar o valor nutritivo do material ensilado é a inclusão de produtos mais protéicos.

A adição de leguminosas é uma opção para proporcionar aumento no teor de proteína bruta $(\mathrm{PB})$ da silagem fornecida aos animais, além de supri-la com maior quantidade de cálcio e fósforo (BAXTER et al., 1984). A leucena (Leucaena leucocephala) é uma leguminosa arbustiva, perene, que apresenta raízes profundas, característica que lhe confere excelente tolerância à seca. Altamente palatável, produz elevadas quantidades de forragem com altos teores de proteína e minerais, notadamente em solos de alta fertilidade natural, sendo, portanto, uma alternativa de baixo custo para a substituição parcial dos produtos comerciais comumente utilizados na suplementação animal (COSTA, 1987).

O efeito da adição de leucena na composição químico-bromatológica da silagem de capim-elefante foi avaliado por Pereira et al. (1998). Os autores não observaram influência da inclusão de leucena nos níveis de $0,10,20,30$ e 40\%, nos teores de matéria seca (MS), fibra em detergente ácido (FDA) e energia bruta (EB), porém, registraram aumento significativo nos teores de matéria orgânica $(\mathrm{MO})$, proteína bruta $(\mathrm{PB})$, extrato etéreo $(\mathrm{EE})$ e lignina. Os teores de matéria mineral, fibra em detergente neutro, celulose e hemicelulose decresceram significativamente com a inclusão de leucena.

Magalhães et al. (2003) observaram que a adição de 20 e $40 \%$ de forragem de leucena aumentou, significativamente, os teores de PB da silagem de capimelefante (Pennisetum purpureum Schum.) de 4,04\% para $6,54 \%$ e $7,60 \%$, respectivamente, representando incrementos de $61,88 \%$ e $88,11 \%$. Esses resultados foram associados à substituição do capim-elefante com $4,31 \%$ de PB pela leucena com 16,08\%.

Estudos da associação de milho com a soja (Glycine $\max ($ L.) Merril) foram realizados por Martins e Rodriguez (1979), Evangelista et al. (1983, 1991), Zago et al. (1985) e Obeid et al. (1992a,b).

Evangelista et al. $(1988,1991)$ concluíram que $70 \%$ de soja consorciada com milho proporcionaram maiores consumos de matéria seca e proteína bruta em ovinos e que o rendimento forrageiro não foi alterado pela presença da soja nos arranjos culturais.

Eichelberger et al. (1997a) testaram a associação milho-soja nas proporções de 0, 10, 20, 30, 40 e 50\% de forragem de soja. Concluíram que a inclusão de até $50 \%$ de soja na mistura da silagem é uma alternativa viável para a melhoria da qualidade da silagem de milho no que se refere aos teores de PB, cálcio e fósforo.

Conduziu-se este trabalho com o objetivo de avaliar os efeitos da adição de níveis crescentes de forragem de leucena no valor nutritivo da silagem de milho.

\section{MATERIAL E MÉTODOS}

O experimento foi realizado nas dependências do Departamento de Zootecnia da Universidade Federal de Lavras-MG. Segundo Castro Neto et al. (1980), Lavras está situada a $21^{\circ} 14^{\prime}$ de Latitude Sul e $45^{\circ} 00^{\prime}$ de Longitude Oeste de Greenwich, com altitude média de $910 \mathrm{~m}$. O clima, segundo a classificação de Köppen, é do tipo Cwb, caracterizando-se por duas estações bem definidas: seca (abril a setembro) e chuvosa (outubro a março). A precipitação anual média é de $1493 \mathrm{~mm}$ e as temperaturas médias de máxima e mínima são de 26,0 e $14,6^{\circ} \mathrm{C}$, respectivamente.

O milho 'DK-901' foi plantado em dezembro/2002 e colhido em abril/2003, sendo o corte realizado a $10 \mathrm{~cm}$ de altura. A leucena foi cortada no mesmo dia da colheita do milho, selecionando-se ramos com diâmetro de até $10 \mathrm{~mm}$. As forragens foram picadas individualmente em picadeira convencional de forragem em partículas de 1 a $2 \mathrm{~cm}$.

$\mathrm{O}$ delineamento experimental usado foi o inteiramente casualizado com cinco tratamentos e três repetições. Os tratamentos consistiram de silagem de milho contendo $0,10,20,30$ e $40 \%$ de forragem de leucena com base na matéria verde.

Para o preparo das silagens mistas, as forragens foram pesadas nas devidas proporções e cada mistura foi homogeneizada antes de ser ensilada. Como silos experimentais, utilizaram-se canos de PVC com $10 \mathrm{~cm}$ de diâmetro e $50 \mathrm{~cm}$ de comprimento, com capacidade para 2,50 $\mathrm{kg}$ de silagem $\left(600 \mathrm{~kg} / \mathrm{m}^{3}\right)$. A compactação foi realizada com soquetes de ferro e o fechamento com tampas de PVC dotadas de válvula tipo Bunsen, lacradas com fita adesiva.

Foram retiradas amostras do material original picado antes da ensilagem para determinação do teor de matéria seca (MS) a $65^{\circ} \mathrm{C}$, em estufa de ventilação forçada, segundo metodologia da AOAC (1975) e para determinação do poder-tampão, conforme o método de Playne e McDonald (1966). As amostras utilizadas para determinação do poder-tampão foram congeladas.

Os silos foram abertos 30 dias após a ensilagem. Os $5 \mathrm{~cm}$ das porções superior e inferior dos silos foram descartados. A silagem foi homogeneizada e retiradas amostras para determinação do teor de nitrogênio amoniacal $\left(\mathrm{N}-\mathrm{NH}_{3}\right)$, segundo método descrito por Tosi (1973), as quais foram congeladas, e para a determinação 
do $\mathrm{pH}$, que foi realizada imediatamente após a abertura dos silos, utilizaram-se $9 \mathrm{~g}$ de amostra imersa em $60 \mathrm{~mL}$ de água destilada, por 30 minutos, com posterior leitura em peagâmetro. Também foram retiradas amostras para determinação da $\mathrm{MS}$ a $65^{\circ} \mathrm{C}$. As amostras pré-secas foram moídas em moinho estacionário com peneira de $1 \mathrm{~mm}$ para determinação dos teores de matéria seca (MS) e de proteína bruta $(\mathrm{PB})$, conforme métodos recomendados pela AOAC (1975), e dos teores de fibra em detergente neutro e ácido (FDN e FDA), segundo as técnicas descritas por Goering e Soest (1970). Os dados obtidos foram submetidos à análise de variância e regressão, conforme metodologia descrita por Banzato e Kronka (1992), utilizando-se o software SAEG (RIBEIRO JÚNIOR, 2001).

\section{RESULTADOS E DISCUSSÃO}

\section{Matéria seca}

Não houve efeito dos níveis de inclusão de leucena para as variáveis teor de MS da forragem original (MSO) e teor de MS da silagem (MSS). Porém, os teores de matéria seca nas silagens mantiveram a mesma tendência dos valores observados no material antes de ser ensilado (Quadro 1).

A colheita do milho no estádio adequado de maturidade é importante para uma maior produção de silagem de alto valor nutritivo, obtida ao menor custo possível (FERREIRA, 1990). Nussio e Manzano (1999) recomendaram cortar o milho em estágios mais avançados de maturidade, quando apresentar de 30 a $37 \%$ de matéria seca (MS). O corte do milho com a planta apresentando 24 a $28 \%$ de MS resulta em menor produção de matéria seca e silagem de baixa qualidade, apresentando fermentação indesejável, alta umidade, baixo $\mathrm{pH}$ e baixo teor de grãos, apesar do alto nível de açúcares solúveis (NUSSIO e MANZANO, 1999).

QUADRO 1 - Teores de matéria seca da forragem original (MSO) e das silagens de milho (MSS) em função dos diferentes níveis de inclusão de leucena

\begin{tabular}{|c|c|c|}
\hline $\begin{array}{c}\text { Níveis de inclusão de } \\
\text { leucena (\%) }\end{array}$ & MSO (\%) & MSS (\%) \\
\hline 0 & 28,18 & 27,34 \\
10 & 27,96 & 27,22 \\
20 & 27,85 & 27,00 \\
30 & 27,54 & 26,80 \\
40 & 27,05 & 26,34 \\
\hline
\end{tabular}

O teor de MS do milho antes de ensilar (MSA) foi de $28,18 \%$ e a inclusão de forragem de leucena não reduziu de forma significativa esse teor. Entretando, do nível $10 \%$ de inclusão até $40 \%$ houve uma redução nos teores de MSA de 27,96\% a 27,05\%, situando essas silagens em níveis de matéria seca abaixo do recomendado para uma boa fermentação.

Quando comparados à forragem que lhe deu origem, os teores de MS das silagens (MSS) apresentaram-se, em média, 2,8\% inferiores, o que é normal, considerando as perdas ocorridas durante o processo de fermentação que, segundo Faria (1986), em condições normais, ocorre em média de $10 \%$. A despeito do teor de MS, as perdas foram pequenas, indicando boas condições de conservação. O teor de MS da silagem de milho exclusivo foi de $27,34 \%$, e a inclusão de $40 \%$ de forragem de leucena reduziu o teor de MSS para 26,34\%, porém, sem significância estatística. Esses resultados estão de acordo com Evangelista et al. (1983), Obeid et al. (1985) e Zago et al. (1985), que também não registraram influência da soja sobre o teor de MS das silagens de milho e Pereira et al. (1998), que não observaram efeito da inclusão de leucena no teor de MS da silagem de capim-elefante.

Entretanto, Carneiro e Rodriguez (1980) registraram elevação nos teores de matéria seca da silagem de milho de 26 para $30 \%$ com a inclusão de $40 \%$ de soja. Por outro lado, Evangelista (1986), trabalhando com silagens provenientes do consórcio de milho com soja, observou que a presença de soja reduziu o teor de MS das silagens, em razão da participação da soja na MS total, que variou de 15 a $27 \%$. A inclusão de $40 \%$ de forragem de soja promoveu a redução do teor de MS da silagem de milho exclusivo de $27,65 \%$ para $25,36 \%$ (EICHELBERGER et al., 1997a).

\section{Poder-tampão e pH}

Houve resposta linear em função do aumento nos níveis de inclusão de leucena na forragem de milho para as variáveis poder-tampão e $\mathrm{pH}$ das silagens (Quadro 2).

A acidez é ponto importante no processo de avaliação da qualidade das silagens, tendo em vista que as bactérias butíricas são muito sensíveis ao ambiente ácido. Desse modo, segundo Tayarol Martin (1997), quanto mais rapidamente o $\mathrm{pH}$ cair para valores próximos a 4,0 , mais elas serão inibidas, resultando na maior conservação do material ensilado com menores perdas pelas transformações na fração protéica. A capacidade tamponante é medida por meio da quantidade em meq de $\mathrm{H}^{+}$que é gasta para abaixar os valores de $\mathrm{pH}$ de 6 até

Ciênc. agrotec., Lavras, v. 28, n. 4, p. 924-930, jul./ago., 2004 
4 de uma forragem, indicando a resistência dos componentes orgânicos e inorgânicos à acidificação, durante a conservação (MCDONALD e HENDERSON, 1962, citados por ALMEIDA FILHO, 1996). Uma característica das leguminosas é o baixo conteúdo de carboidratos solúveis e alto poder-tampão promovido por aminoácidos residuais e presença de cátions, como $\mathrm{K}^{+}, \mathrm{Ca}^{2+}$ e $\mathrm{Mg}^{2+}$, que neutralizam os ácidos orgânicos formados pela fermentação, impedindo a queda do pH (LIMA, 1992). No presente trabalho, observou-se resposta linear da variável poder-tampão (PT) em função do aumento nos níveis de inclusão de leucena na silagem de milho. Do nível 0 de inclusão ao $40 \%$, houve uma variação no poder-tampão da forragem de 14,02 a 26,07 eq.mg $\mathrm{HCl} / 100$ g MS, correspondendo a um aumento de $85,95 \%$. Lavezzo et al. (1997) registraram um poder-tampão de 15,88 eq.mg $\mathrm{HCl} / 100 \mathrm{~g}$ MS para a silagem de milho com $28,65 \%$ de MS.

De acordo com Ruiz e Ruiz (1990), as silagens são classificadas como excelentes, quando apresentam $\mathrm{pH}$ menores que 4,6 para teores de MS variando de 26 a $35 \%$. O pH variou de 3,32 para a silagem de milho puro até 3,58 para silagem com $40 \%$ de leucena, com um incremento de 7,83\%. Esse aumento já era esperado, pois, segundo Eichelberger et al. (1997b), a mistura de leguminosa ao milho tende a aumentar o $\mathrm{pH}$ da silagem pelo maior poder-tampão da leguminosa. Resultados semelhantes foram encontrados por Lima (1996), que avaliou silagens de capim-elefante adicionada à soja e Eichelberger et al. (1997a) e Obeid et al. (1992a), trabalhando com associações milho e soja. Resultados diferentes foram obtidos por Evangelista (1986) e Lempp et al. (2000), que não observaram alteração no $\mathrm{pH}$ das silagens de milho com a adição de soja.

\section{Proteína Bruta, Nitrogênio Amoniacal, Fibra em Detergente Neutro, Fibra em Detergente Ácido}

Houve resposta linear para as variáveis proteína bruta $(\mathrm{PB})$, nitrogênio amoniacal $\left(\mathrm{N}-\mathrm{NH}_{3}\right)$, fibra em detergente neutro (FDN) e fibra em detergente ácido (FDA) em função do aumento nos níveis de inclusão de leucena na silagem de milho (Quadro 3).

QUADRO 2 - Equações de regressão para poder-tampão do material original e pH das silagens de milho em função dos diferentes níveis de inclusão de leucena.

\begin{tabular}{|c|c|c|}
\hline Características avaliadas & Equações & $\mathbf{R}^{\mathbf{2}}$ \\
\hline PT (eq.mg HCl/100 g MS) & $\mathrm{Y}=14,0182+0,301377 \mathrm{x}$ & 0,9849 \\
$\mathrm{pH}$ & $\mathrm{Y}=3,31933+0,006500 \mathrm{x}$ & 0,9926 \\
\hline
\end{tabular}

QUADRO 3 - Equações de regressão para os teores de proteína bruta (PB), nitrogênio amoniacal $\left(\mathrm{N}_{-} \mathrm{NH}_{3}\right)$, fibra em detergente neutro (FDN) e fibra em detergente ácido (FDA) das silagens de milho em função dos diferentes níveis de inclusão de leucena.

\begin{tabular}{|c|c|c|}
\hline Características avaliadas & Equações & $\mathbf{R}^{\mathbf{2}}$ \\
\hline $\mathrm{PB}(\% \mathrm{MS})$ & $\mathrm{Y}=7,85267+0,151167 \mathrm{x}$ & 0,9706 \\
$\mathrm{~N}^{-N_{3}}$ (\% N-Total) & $\mathrm{Y}=1,17067+0,0118667 \mathrm{x}$ & 0,9932 \\
$\mathrm{FDN}(\% \mathrm{MS})$ & $\mathrm{Y}=46,7440-0,138567 \mathrm{x}$ & 0,8097 \\
FDA (\% MS) & $\mathrm{Y}=27,3180-0,0690 \mathrm{x}$ & 0,6900 \\
\hline
\end{tabular}


Todos os tratamentos apresentaram teores de $\mathrm{PB}$ acima de $7 \%$, considerado o limite mínimo para o desenvolvimento adequado das bactérias ruminais (SOEST, 1994). Segundo Ruiz e Ruiz (1990), teores de PB na MS inferiores a 7\% afetam de forma negativa o consumo e a digestibilidade de nutrientes devido à deficiência de nitrogênio no rúmen, o que pode se agravar se a proteína da silagem for solubilizada na forma de amônia.

Com base nesse critério todas as silagens produzidas podem ser consideradas como adequadas, já que os teores de proteína bruta obtidos variaram de 7,85 para a silagem de milho exclusivo a $13,90 \%$ para a silagem com $40 \%$ de leucena, correspondendo a um incremento de $77,07 \%$. Pereira et al. (1998) encontraram teores de PB variando de 4,37\% em silagem de capim-elefante puro até $10,93 \%$ em silagens de capim-elefante com nível de inclusão de $40 \%$ de leucena. Carneiro e Rodriguez (1980) obtiveram aumento da ordem de $64 \%$ com a inclusão de $40 \%$ de soja na silagem de milho. Efeitos positivos no teor de PB de silagens de milho e soja também foram obtidos por Evangelista et al. (1983), Evangelista (1986), Zago et al. (1985), Gomide et al. (1987), Obeid et al. (1992a,b), Eichelberger et al. (1997a,b) e Lempp et al. (2000). Obeid et al. (1992b) consorciaram o milho com soja, lablab, guandu, crotalária e mucuna-preta e concluíram que as leguminosas proporcionaram aumento no teor protéico das silagens.

Durante a fermentação no silo, uma fração da PB é rapidamente degradada a nitrogênio não-protéico. A presença de nitrogênio amoniacal é um indicador da extensão com que ocorreu a atividade de clostrídeos, uma vez que esse produto é produzido em pequenas quantidades por outros microrganismos da silagem e enzimas da planta (JOBIM e GONÇALVES, 2003). Essa é uma característica importante na avaliação da silagem, pois contribui para a elevação do $\mathrm{pH}$ da silagem, sendo, por isso, um indicativo de fermentação indesejável (MILLER et al., 1961, citados por VALENTE, 1977) pois, segundo McDonald et al. (1991), os teores de $\mathrm{N}$ amoniacal são geralmente elevados nas silagens mal-conservadas. O nitrogênio amoniacal, expresso em \% N-Total, indica a quantidade de proteína degradada durante a fase de fermentação ou ainda a ocorrência de um aquecimento excessivo da massa no silo por reações de Maillard (PIGURINA, 1991). Conforme Silveira (1975), as silagens que apresentam valores de $\mathrm{N}-\mathrm{NH}_{3}$ até $8 \%$ do N-Total são consideradas de ótima qualidade.

Os teores de $\mathrm{N}-\mathrm{NH}_{3}$ variaram de 1,17 a $1,64 \%$ do N-Total, respectivamente, para a silagem de milho exclusivo e adicionada de $40 \%$ de forragem de leucena. Esses teores são considerados baixos, indicando uma baixa degradação da PB. Lavezzo et al. (1997) encontraram teores de nitrogênio amoniacal de 11,24\% para silagem de milho com teor de $28,65 \%$ de MS.

A adição de forragem de leucena promoveu decréscimos nos teores de FDN e FDA das silagens possivelmente devido a maiores teores desses componentes observados na silagem de milho exclusivo, ou seja, 46,74 e $27,32 \%$, respectivamente. A adição de $40 \%$ de leucena promoveu uma redução de $11,85 \%$ nos teores de FDN e de 10,10\% nos teores de FDA das silagens. Eichelberger et al. (1997a) verificaram que a adição de $40 \%$ de forragem de soja ao milho promoveu a redução no teor de FDN de 65,37 \% para 60,02\% e a elevação no teor de FDA de 32,14\% para 33,90\%. A inclusão de soja até o nível de $40 \%$ causou redução nos teores de FDN de silagens de capim-elefante e não promoveu diferenças significativas nos teores de FDA (PEREIRA et al., 1998). Em trabalho realizado por Eichelberger et al. (1997b), a inclusão de soja promoveu aumento no teor de FDN da silagem de milho, porém, a inclusão de feijão miúdo promoveu uma redução nesse teor. Os teores de FDA dessas silagens não foram alterados pela inclusão das leguminosas. Por outro lado, Gomide et al. (1987) não observaram diferenças nos teores de FDN em silagens provenientes dos consórcios de soja com milho normal, milho-anão, sorgo forrageiro e sorgo granífero, quando a soja perfazia 10, 20, 30 e $40 \%$ da mistura.

\section{CONCLUSÕES}

A inclusão de leucena até o nível de $40 \%$ melhora a qualidade das silagens de milho produzidas, principalmente em razão do aumento do teor de proteína bruta da redução dos teores de fibra em detergente ácido e fibra em detergente neutro que ocorrem nesse volumoso.

\section{REFERÊNCIAS BIBLIOGRÁFICAS}

ALMEIDA FILHO, S. L. de. Avaliação de cultivares de milho (Zea mays L.) para silagem. 1996. 53 f. Dissertação (Mestrado em Zootecnia) - Universidade Federal de Viçosa, Viçosa, 1996.

ASSOCIATION OF OFFICIAL AGRICULTURAL CHEMISTS. Official methods of analysis of the association of official analytical chemists. Washington, USDA, 1975. $1015 \mathrm{p}$.

BANZATO, D. A.; KRONKA, S. Experimentação agrícola. Jaboticabal: FUNEP, 1992. 247 p. 
BAXTER, H. D.; MONTGOMERY, M. J.; OWEN, J. R. Comparison of soybean-grain sorghum silage with corn silage for lactating cows. Journal Dairy Science, Syracuse, v. 67, n. 1, p. 88-96, 1984.

CARNEIRO, A. M.; RODRIGUEZ, N. M. Influência da leguminosa na qualidade da silagem de milho. Arquivos da Escola de Veterinária da UFMG, Belo Horizonte, v. 32, n. 3, p. 415-420, 1980.

CASTRO NETO, P.; SEDYIMA, G. C.; VILELA, E. A. Probabilidade de ocorrência de períodos secos em Lavras, MG. Ciência e Prática, Lavras, v. 4, n. 1, p. 46-55, 1980.

COSTA, N. de L. Recomendações técnicas para o cultivo de leucena. Porto Velho: EMBRAPA-UEPAE, 1987. 8 p. (Comunicado Técnico, 50).

EICHELBERGER，L.; SIEWERDT， L.; SILVEIRA JÚNIOR, P. Efeitos da inclusão de níveis crescentes de forragem de soja e uso de inoculante na qualidade da silagem de milho. Revista Brasileira de Zootecnia, Viçosa, v. 26, n. 5, p. 867-874, 1997a.

EICHELBERGER，L.; SIEWERDT, L.; SILVEIRA JÚNIOR, P. Efeitos da inclusão de soja ou feijão miúdo e uso de inoculante na qualidade da silagem de milho. Revista Brasileira de Zootecnia, Viçosa, v. 26, n. 4, p. 667-674, 1997b.

EVANGELISTA, A. R. Silagem de milho ou sorgo com soja. Lavras: ESAL, 1986. 19 p. (Boletim Técnico, 8).

EVANGELISTA, A. R.; GARCIA, R.; GALVÃO, J. D. Efeito da associação milho-soja no valor nutritivo da silagem. Revista da Sociedade Brasileira de Zootecnia, Viçosa, v. 12, n. 1, p. 50-59, 1983.

EVANGELISTA, A. R.; GARCIA, R.; GOMIDE, J. A. Silagem de milho e soja para novilhos em confinamento. In: REUNIÃO ANUAL DA SOCIEDADE BRASILEIRA DE ZOOTECNIA, 21., 1984, Belo Horizonte. Anais... Belo Horizonte: SBZ, 1984. p. 324.

EVANGELISTA, A. R.; GARCIA, R.; OBEID, J. A. Consórcio milho-soja: rendimento forrageiro, qualidade e valor nutritivo das silagens. Revista da Sociedade Brasileira de Zootecnia, Viçosa, v. 20, n. 6, p. 578-584, 1991.

EVANGELISTA, A. R.; LIMA, J. A. Silagens do cultivo ao silo. Lavras: UFLA, 2000. 196 p.
EVANGELISTA, A. R.; TEIXEIRA, J. C.; REZENDE, P. M. de; PEREZ, J. R. O.; TOLEDO, J. A. F. de. Níveis de associação de soja (Glycine max (L.) Merril) com o milho para ensilar, valor nutritivo. In: REUNIÃO ANUAL DA SOCIEDADE BRASILEIRA DE ZOOTECNIA, 25., 1988, Viçosa. Anais... Viçosa: SBZ, 1988. p. 192.

FARIA, V. P. Técnicas de produção de silagens. In: PEIXOTO, A. M.; MOURA, J. C.; FARIA, V. P. Pastagens: fundamentos da exploração racional. Piracicaba: FEALQ, 1986. p. 323-348.

FERREIRA, J. J. Aspectos vegetativos da planta de milho e momento da colheita para ensilagem. Informe Agropecuário, Belo Horizonte, v. 14, n. 164, p. 47-49, 1990.

GOERING, H. K.; SOEST, P. J. van. Forage fiber analysis: apparatus, reagents, procedures and some applications. Washington: USDA, 1970. (Agricultural Handbook, 379).

GOMIDE, J. A.; ZAGO, C. P.; CRUZ, M. E.; EVANGELISTA, A. R.; GARCIA, R.; OBEID, J. A. Milho e sorgo em cultivos puros ou consorciados com soja para produção de silagens Revista da Sociedade Brasileira de Zootecnia, Viçosa, v. 16, n. 4, p. 308316, 1987.

JOBIM, C. C.; GONÇALVES, G. D. Microbiologia de forragens conservadas. In: REIS, R. A.; BERNARDES, T. F.; SIQUEIRA, G. R.; MOREIRA, A. L. (Eds.). Volumosos na produção de ruminantes: valor alimentício. Jaboticabal: Funep, 2003. p. $1-26$.

LAVEZZO, W.; LAVEZZO, O. E. N. M.; CAMPOS NETO, O. Estádio de desenvolvimento do milho: 1. efeito sobre a produção, composição da planta e qualidade da silagem. Revista Brasileira de Zootecnia, v. 26, n. 4, p. 675-682, 1997.

LEMPP, B.; MORAIS, M. G.; SOUZA, L. C. F. Produção de milho em cultivo exclusivo ou consorciado com soja e qualidade de suas silagens. Arquivo Brasileiro de Medicina Veterinária e Zootecnia, Belo Horizonte, v. 52, n. 3, p. 243-249, jun. 2000.

LIMA, J. A. Qualidade e valor nutritivo da silagem mista de capim-elefante (Pennisetum purpureum Schum.) e soja (Glycine max (L.) Merril), com e sem adição de farelo de trigo. 1992. 69 f. Dissertação 
(Mestrado em Zootecnia) - Universidade Federal de Lavras, Lavras, 1992.

McDONALD, P.; HENDERSON, A. R.; HERON, S. J. E. Microrganisms. In: The biochemistry of silage. Chicago: [s.n.], 1991. p. 81-151.

MAGAlhães, J. A.; LOPES, E. A.; COSTA, N. de L.; TOWSEND, C. R.; RODRIGUES, B. H. N. Efeito da adição da leucena sobre os teores de proteína bruta e minerais na silagem de capim-elefante. In: CONGRESSO NACIONAL DE ZOOTECNIAZOOTEC, 13., 2003, Uberaba. Anais... Uberaba: FAZU, 2003. p. 382-386.

MARTINS, A.; RODRIGUEZ, N. M. Influência da leguminosa na qualidade da silagem de milho. In: REUNIÃO ANUAL DA SOCIEDADE BRASILEIRA DE ZOOTECNIA, 16., 1979, Curitiba. Anais... Curitiba: SBZ, 1979, p. 15.

NUSSIO, L. G.; MANZANO, R. P. Silagem de milho. In: SIMPÓSIO SOBRE NUTRIÇÃO DE BOVINOS, 7., 1999, Piracicaba. Anais... Piracicaba: FEALQ, 1999. p. 27-46.

OBEID, J. A.; ZAGO, C. P.; GOMIDE, J. A. Qualidade e valor nutritivo da silagem consorciada de milho (Zea mays L.) com soja anual (Glycine max (L.) Merril). Revista da Sociedade Brasileira de Zootecnia, Viçosa, v. 14, n. 4, p. 439-446, 1985.

OBEID, J. A.; GOMIDE, J. A.; CRUZ, M. E. Silagem de milho (Zea mays, L.) consorciada com leguminosas na alimentação de novilhos de corte em confinamento. Revista da Sociedade Brasileira de Zootecnia, Viçosa, v. 21, p. 39-44, 1992 a.

OBEID, J. A.; GOMIDE, J. A.; CRUZ, M. E. Silagem consorciada de milho (Zea mays, L.) com leguminosas: produção e composição bromatológica. Revista da Sociedade Brasileira de Zootecnia, Viçosa, v. 21, n. 1, p. 33-38, 1992 b.

OLIVEIRA, J. S. Avaliação de cultivares de milho para silagem: resultados preliminares do ano agrícola 2000/2001. Juiz de Fora: EMBRAPA Gado de Leite, 2001. 40 p. (Circular Técnica, 65).

PEREIRA, J. A.; AZEVEDO, A. R. de; ALVES, A. A.; PIMENTEL, J. C. M.; VELOSO JÚNIOR, R. R.; CASTRO, A. B. de. Composição químicobromatológica da silagem de capim-elefante com diferentes níveis de leucena. In: REUNIÃO ANUAL DA SOCIEDADE BRASILEIRA DE ZOOTECNIA,
35., 1998, Botucatu. Anais... Botucatu: SBZ, 1998. CD-ROM.

PIGURINA, F. Factores que afectan em valor nutritivo y la calidad de fermentacion de ensilajes. In: ______. Pasturas y producción animal de áreas organaderia intensiva. Montevideo: Instituto Nacional de Investigación Agropecuaria, 1991. p. 77-92. (Serie Tecnica, 15).

PLAYNE, M. J.; McDONALD, P. The buffering constituents of herbage and of silage. Journal of the Science of Food and Agriculture, London, v. 17, p. 262-268, 1966.

RIBEIRO JÚNIOR, J. I. Análises estatísticas no SAEG. Viçosa: UFV, 2001. 301 p.

RUIZ, E. M.; RUIZ, A. Metodologias para investigaciones sobre conservación y utilizacióin de ensilagens. In: INSTITUTO INTERAMERICANO DE COPERACIÓN PARA LA AGRICULTURA. Nutrición de ruminantes: guia metodológico de cooperación. San José, 1990. p. 179-218.

SILVEIRA, A. C. Técnicas para produção de silagens. In: SIMPÓSIO SOBRE MANEJO DA PASTAGEM, 2., 1975, Piracicaba. Anais... Piracicaba: ESALQ, 1975. p. 156-186.

SOEST, P. J. van. Nutritional ecology of the ruminant. 2. ed. Ithaca: Cornell University, 1994. $476 \mathrm{p}$.

TAYAROL MARTIN, L. C. T. Bovinos: volumosos suplementares. São Paulo: Nobel, 1997. $143 \mathrm{p}$

TOSI, H. Ensilagem de gramíneas tropicais sob diferentes tratamentos. 1973. 107 f. Tese (Doutorado em Produção Animal) - Universidade Estadual Júlio Mesquita Filho, Botucatu, 1973.

VALENTE, J. O. Produtividade de duas variedades de milho e quatro variedades de sorgo e valor nutritivo de suas silagens. 1977. 76 f. Dissertação (Mestrado em Zootecnia) - Universidade Federal de Viçosa, Viçosa, 1977

VILELA, D. Aditivos para silagem de plantas de clima tropical. In: REUNIÃO ANUAL DA SOCIEDADE BRASILEIRA DE ZOOTECNIA, 35., 1998, Botucatu. Anais... Botucatu: SBZ, 1998. p. 73-108.

Ciênc. agrotec., Lavras, v. 28, n. 4, p. 924-930, jul./ago., 2004 
ZAGO, C. P.; OBEID, J. A.; GOMIDE, J. A. Desempenho de novilhos zebu alimentados com silagens consorciadas de milho (Zea mays, L.) com soja anual (Glycine max L. Merril). Revista da Sociedade Brasileira de Zootecnia, Viçosa, v. 14, n. 3, p. 510514, 1985. 